\title{
Bureaucratic Red Tape and Discretion of Street Level Bureaucracy:
}

\author{
Implication of Food Diversification Policy in Indonesia
}

\author{
Didik Iskandar* \\ Student Doctoral Program of Public Administration Science \\ Universitas Hasanuddin \\ Makassar, Indonesia \\ *didik.iskandar27@gmail.com
}

\author{
Alwi \\ Lecture of Department of Administration Science \\ Universitas Hasanuddin \\ Makassar, Indonesia \\ alwifisip@gmail.com
}

\begin{abstract}
Street level bureaucracy is a government employee who provides community services where their activities are often trapped in the bureaucracy red tape phenomenon which is formalized and too procedural. This condition sometimes requires the actors involved to take discretionary action. The main objective of this study is to explain the relationship between red tape and discretion in the implementation of food diversification policies. The methodological approach used in this study is qualitative with an explanatory type to explain the implications of the bureaucratic red tape phenomenon as well as discretion making by street level bureaucracy on the implementation of food diversification policies. The theoretical pattern used is the policy implementation network, namely the relative stability of a network's membership, the network's relative insularity, the strength of resource dependencies in overcoming bureaucratic red tape and supporting discretion by street level bureaucracy. The results show that there is a red tape phenomenon in the bureaucracy, such as rigid and convoluted procedures as well as formalization of hierarchical rules and structures that lead to policy delay. The discretion taken by the actors has also not been able to optimally answer public needs. In addition, the policy network sector, namely the relative stability of a network's membership, the network's relative insularity, the strength of resource dependencies has not been able to run effectively according to what has been understood.
\end{abstract}

Keywords-bureaucratic red tape, diskresi, street-level bureaucracy, policy implementation, and food diversivication

\section{INTRODUCTION}

The public bureaucracy in Indonesia continues to be demanded to accelerate in the field of public services in all sectors including the food sector, especially in food diversification policies. The role of the public bureaucracy as an institution that implements formulated policies makes it obligatory to carry out an adaptation process to changing conditions in the current era of disruption. The current public bureaucracy tends to work guided by hierarchy, procedure, control and regulation which are the basic principles of the Weberian bureaucracy and have shaped the character of the public bureaucracy from the past until now [1]. In addition, amidst rapid changes, the bureaucracy maintains hierarchical and rigid procedures, and continues to strive to standardize and formalize to support a stable environment.

Some parties consider that rigidity in adhering to these principles is the failure of the public bureaucracy in Indonesia to respond to changes and increasingly demanding public demands. The public bureaucracy in Indonesia sometimes loses space to innovate and develop creativity also due to a culture that tends to consistency, routine, and certainty [2]. The effort to create a public bureaucracy from an institutional civilservice model that leads to a citizen-centric governance model will be more difficult if the behavior and habits in the bureaucratic work environment still adhere to conventional patterns such as those in the Weberian bureaucracy concept. The rigid, hierarchical, and formalized Weberian bureaucratic model in the provision of public services is actually considered a bureaucratic red tape phenomenon.

The phenomenon of bureaucratic red tape is certainly not new in public bureaucracy which has quite a complex scope. Bureaucratic red tape is transformed as a pattern patterned within the scope of work of the public bureaucracy, thus avoiding efforts to streamline services which sometimes ignore public interests. In its most general form, red tape is often defined as regulations, procedures, rules and procedures in the service that become too convoluted and deviant which sometimes occurs due to natural tendencies in organizations and individual bureaucrats and is created from their routine activities. The bureaucratic group that has the potential to create red tape phenomenon is the street level bureaucracy group.

Street level bureaucracy, as a component of policy implementation and also the front line of the public bureaucracy in terms of service delivery, is often trapped in the red tape phenomenon. In a situation like this, the street level bureaucracy is often faced with a dilemma that demands discretion. Discretionary action by street level bureaucracy to promote their position as service providers and also to 
encourage people to believe that they hold the key to bringing prosperity to any public service [3]. To the extent that complexity and intervention are deemed necessary for effective services, excretion will remain a characteristic of street level bureaucracy in public service activities.

Discretion becomes a crucial issue in public policy as there are demands for the resolution of various public problems, all of which are still not regulated in standard regulations. The low ability of the bureaucracy in exercising discretion can not only be an indicator of the low level of responsiveness of the bureaucracy in understanding the aspirations and needs of the public, as well as an indicator to show that the bureaucracy is still acting on rigidly applied regulations [4]. The working pattern and thinking of the bureaucratic apparatus that are still shackled to a procedural technical orientation becomes a gap in creating policy delays so that it can slow down the process of implementing government programs, even stagnating. In terms of enforcing discretionary measures in relation to fulfilling public interests, the current policy network approach is considered capable of supporting government activities in creating effective policy performance.

Policy networks are often termed a pattern of relationships formed as a result of a coalition between actors, be it government, society or the private sector. The term actor is used to represent the existence of stakeholders who contribute and share with each other the same goal. The policy implementation network is a concept that is currently developing in realizing policy objectives that are oriented towards meeting public needs. The network model in public policy implementation is very important due to the fact that stakeholders in policy implementation have the same interests and goals. Model of policy networks has probably been employed more often than any other in the study of governance. Simply put, the model assumes that three key variables determine what type of policy network exists in a specific sector: the relative stability of a network's membership, the network's relative insularity, the strength of resource dependencies [5].

One of the government programs that has also become a national strategic policy is the food diversification policy. Of course, strengthening government programs in an effort to support food diversification policies has been carried out from the president's generation in each period. However, the various efforts that have been made so far have not matched what has been targeted or in other words have not been fully effective. Law Number 18 of 2012 concerning food and government regulation Number 17 of 2015 concerning Food Security and Nutrition, have also mandated food diversification to reduce dependence on rice and flour consumption. The Ministry of Agriculture places the local food diversification program as the second way of action (CB2) in the program to increase food availability. The program will focus on increasing the supply and consumption of corn, cassava, sago, potato, banana and taro to meet the nutritional adequacy of the community so that they can live healthy, active and productive lives.
The implementation of the national food diversification policy is faced with accelerating the availability, access and consumption of local food. As one of the areas categorized as a food barn, Bone Regency certainly faces several obstacles related to the implementation of food diversification policies by the government. This comes from the side of the implementation of programs run by the government, which some people think that the implementation is still convoluted and requires policies that are responsive to the current situation. In addition, in its implementation, the community considers that it is still difficult to get access related to the bone district government food diversification program.

In the implementation of third-generation policies, the focus is on how to design policies and policy networks and what the implications are for their implementation and success [6]. The network concept aims to formulate, organize, and implement programs and policies by utilizing various resources or sharing resources that allow the creation of effective and efficient use of resources in order to achieve objectives in the policy implementation process. So if it is related to some of the explanations above, this study aims to see how often the condition of bureaucratic red tape occurs and what forms of discretion are taken and how the role of policy implementation networks, namely the relative stability of a network's membership, the network's relative insularity, the strength of resource dependencies in overcoming red tape and supporting discretion related to food diversification policies in Bone Regency, South Sulawesi Province, Indonesia.

\section{THEORETICAL REVIEW}

\section{A. Discretion and Policy Implementation}

Conceptual discretion is an attempt made by the administrator to solve a particular case that has not been regulated by standard rules. Discretion can be interpreted as a form of leniency in service through policies or decisions given by administrators to service recipients. Administrative discretion is the freedom administrators have to make choice which determine how a policy will be implemented. Administrative discretion is the result of the interaction between politics and administration [7]. Indicators to see discretion can be in the form of a series of actions carried out by bureaucratic officials based on initiatives. Creativity and not making rules as rigid problem solving instruments but on the one hand it becomes a solution that can accommodate various needs without committing violations on the other.

In addition, Lipsky [3] states that theoretically discretion will be a characteristic of street level bureaucracy due to the requirement to elaborate on rules, guidelines and instructions without having to limit the alternatives which are broadly due to two main reasons, namely:

- First, street-level bureaucrats often work in situations too complicated to reduce to programmatic formats.

- Second, street-level bureaucrats work in situations that often require responses to the human dimensions of 
situations. They have discretion because the accepted definitions of their tasks call for sensitive observation and judgment, which are not reducible to programmed formats.

The search for the correct balance between compassion and flexibility on the one hand, and impartiality and rigid rule application on the other hand presents a dialectic of public policy reform.

In the policy implementation process, discretionary action is a common phenomenon because the policy implementation process is very vulnerable to conflicts of interest between several parties. Implementation with regard to various activities directed at the realization of the program, in this case the administrator regulates the ways to organize, interpret and implement the policies that have been selected. As explained in the stages of development that differentiates policy implementation into three main generations, namely the first generation, the second generation and the third generation [6].

The first generation of policy implementation saw implementation as a top down form of implementation where the assessment was determined based on how far there was a deviation from the predetermined design. In the second generation, implementation is a reaction to the weaknesses of the first generation which is bottom up in which the existence of the network of actors, including their goals, strategies and actions is taken into account. Or in other words, policy design must consider the needs and values held by implementers, therefore adaptation and discretion in implementation should be seen as something that should be or is needed. And the implementation of the third generation, the focus of attention is directed to the design of policies and policy networks and their implications for their implementation and success [6]. In addition, Goggin [6] also argues that policy is a message that is strongly influenced by three factors, namely; First, the content of policy: resources, policy benefits, and public involvement; Second, the form of the policy message; and third, the reputation of the communicators.

\section{B. Red Tape and Policy Performance}

The Bureaucracy red tape is a phenomenon that occurs and sometimes recurs in the government administration process. Bureaucracy red tape is present due to the high level of formalization that occurs within organizations [8]. Where formalization is defined as organizational activities manifested in written documents regarding procedures, job descriptions, regulations, and policy manuals. Formalization refers to a number of organizational rules and procedures where the level of formalization at the same time shows the high bureaucratization in an organization.

Red tape in the bureaucracy is very synonymous with the term procedures, rules and regulations where when the three instruments are not running as they should and become redundant, at the same time red tape is present and growing [9]. Red tape as a phenomenon in the bureaucracy can be the initial trigger for the occurrence of bureaucratic pathology. In reality, red tape is often identified with convoluted procedures such as many and less relevant requirements, as well as rigid and hierarchical procedures or stages. The high level of excessive procedures and the various kinds of formalizations that are achieved from each public service delivery has an impact on the low quality of policy performance of a program.

To determine the level of performance in implementing a policy, performance measurement is the main focus [10]. Achieving a policy will go through several fairly long stages. These stages start from; first, policy inputs (resources) that are used to produce products and services from a program; second, processes or activities (activities to produce public products and services), and policy outputs in the form of public products and services that can be enjoyed by the target group; third, direct impact; fourth, medium term impact; and fifth, the longterm impact felt by the target group of a policy program [10]. In its time, the overall policy implementation could be assessed by measuring the achievement of the policy outcome compared to the stated policy objectives, namely what is called policy outcomes impan on society, individuals, and groups in the form of expected change [11].

Thus, in assessing the performance of implementing a policy, the concept of the policy output and the policy outcome are interrelated with one another in terms of assessing the achievement of a policy. The policy output itself has an indicator that is used to determine the direct consequences felt by the target group as a result of the realization of certain policy distribution activities or activities. The policy output indicator is used to determine the direct benefits felt by the target group after they receive the policy output product. The relevant policy performance indicators are strongly influenced by several points, including; access, coverage, frequency, bias, service delivery, accountability, and program suitability with needs [12]. Furthermore, the policy outcome is used to assess the results and impact of the implementation of a policy which consists of three points which are the main indicators in its measurement. First, the initial outcome, which is a policy impact when the target group receives or receives policy products in the form of goods or services. Second, the intermediate outcome, namely after receiving the product from the program, the target group will no longer be in a position it did not want it to be like before receiving the program. Third, the long term outcome. The final goal of a program for a policy product is that the target group will go to prosperity or get out of the desired condition [10].

\section{Network Policy Implementation: Overcoming Red Tape and Supporting Discretion}

The definition of the policy implementation network cannot be separated from the definition of the policy network itself. The policy implementation network can be defined as an act of actor interaction that accommodates all the interests of actors or groups involved in the implementation stage to achieve an objective of public policy. The network concept as one of the approaches used in seeing the phenomenon of policy implementation is often the main concept in measuring the 
extent to which a policy is successful and provides an overview of what kind of constraints and solutions are needed in handling it. The policy implementation network is a study that focuses on the use of resources jointly by stakeholders and the interaction and resources so that the sharing and utilization of resources together shows the efficiency and effectiveness of policy performance [13]. The concept of policy networks was initially influenced by interorganizational theory which emphasized that actors depend on each other, because they need their respective resources to achieve a goal. The interorganizational network approach in policy implementation explains the two relationships that occur between actors, namely the relationship of resource dependence and the relationship of structural dependence.

Policy network analysis starts with three basic assumptions. First, modern governance is frequently non-hierarchical. Few policy solutions are simply imposed by public authorities. Governance involves mutuality and interdependence between public and non-public actors, as well as between different kinds of public actors. Second, the policy process must be disaggregated to be understood because 'relationships between groups and government vary between policy areas' [5]. Rhodes model of policy networks has probably been employed more often than any other in the study of governance. Simply put, the model assumes that three key variables determine what type of policy network exists in a specific sector [5]:

- The relative stability of a network's membership: do the same actors tend to dominate decision-making over time or is membership fluid and dependent on the specific policy issue under discussion?

- The network's relative insularity: is it a cabal which excludes outsiders or is it highly permeable by a variety of actors with different objectives?

- The strength of resource dependencies: do network members depend heavily on each other for valued resources such as money, expertise and legitimacy or are most actors self-sufficient and thus relatively independent of one another.

The policy network concept approach in implementing government programs is used to support all activities that allow relationships between actors who have the same interests and goals. In addition, the application of the policy network concept in terms of discretionary retrieval to resolve the problem of bureaucratic red tape will overcome the existence of policy delays that can hinder policy performance. Strengthening the dimensions contained in the formulation of the policy network concept will assess how far the networkbased program implementation model is, without hierarchical and prioritizing interdependence of resources.

\section{RESEARCH METHODS}

This type of research is a descriptive study with a qualitative approach, which aims to reveal and explain what kind of red tape is happening and the extent of discretion made by street level bureaucracy in the implementation of food diversification policies in Indonesia, especially in Bone Regency. The research strategy used in this research is a case study with an explanatory type to explain the phenomenon in the implementation of food diversification policies based on the context. The type of data used is qualitative data and quantitative data. Sources of data used are based on primary data, namely interviews obtained directly from informants and also secondary data, namely document data derived from news information, papers, books, and journals related to the focus of this research.

Data collection techniques used by researchers include interview techniques, observation, and documentation. Data analysis techniques used are data reduction, display data, and conclusion drawing / verification [14]. Test the validity of the data by triangulating the data independently to cross-check the results of the data from one another such as interviews, observation and documentation to be compared with the data sources obtained by researchers from the results of observations that have been organized, analyzed, and concluded.

\section{RESULTS AND DISCUSSION}

Based on the results of research in the field, several facts were found related to the implementation of food diversification policies in Bone Regency, South Sulawesi Province. There are several red tape phenomena in the bureaucracy in the implementation of food diversification policies, which are conceptually divided into convoluted formalization and procedures. In the context of formalization, the implementation of food diversification policies emphasizes too much a hierarchical structure model that actually provides slow service to the community and farmer groups. Another form of formalization is to see job descriptions, so that some of the street level bureaucracy group tends to ignore tasks that are not their responsibility based on existing internal organizational regulations. Furthermore, in the procedural context, street level bureaucracy, namely agricultural extension workers, tends to be very rigid in seeing the technical guidelines for program implementation and often ignores the needs of the community and farmer groups in the field. For example, the distribution of seeds and fertilizers, for example, extension workers and other field officers are very careful to divide the rations of seeds and fertilizers according to the list given, even though in reality there are actually part of the community and farmer groups who need such assistance more.

Due to the phenomenon of rigidity towards formalization and existing procedures that have been applied for a very long time, it is necessary to identify the extent to which the concept of public policy networks is involved in overcoming the phenomenon of bureaucracy red tape and supporting forms of discretion in the implementation of food diversification policies based on 3 main sectors, namely: 


\section{A. The Relative Stability of a Network's Membership}

This sector emphasizes whether the actors involved in decision making tend to be dominated by the same actors or whether these actors change depending on more specific policy issues. In reality, actors involved in decision making tend to be dominated by the same people. The actors involved in a food diversification program implementing forum have known each other and have had quite a long interaction with one another. This situation makes decisions taken as alternatives in implementing the program tend to be rigid and sometimes do not meet common ground. Thus, the patterns they do are static and do not experience novelty at all.

On the other hand, the involvement of actors who tend to be the same also results in decision-making being dominated by certain people. This made the implementation of the food diversification program in Bone Regency ineffective because there was no alignment of the program from the central government to the regions. And what is most visible is that the implementation of the program in the field has not been able to provide maximum results, namely strengthening the community to shift from a high consumption pattern of rice to lead to increased consumption of local food types that have been declared.

\section{B. The Network's Relative Insularity}

In this sector, it assesses the insularity component involved in decision making whether it is confidential by excluding outsiders or it is very possible for the involvement of various actors with different goals. The component model in a rigid structure and does not provide space for other groups who have the same interests and goals to be involved in decision making is a problem that is quite difficult to overcome. The culture and habits inherent in some actors involved in the implementation of decision making make them unable to be more responsive to increasingly complex public demands related to local food diversification. It is very unfortunate because Bone Regency itself consists of various elements that can be categorized as actors who are quite influential and able to contribute optimally to the implementation of this program.

Insularity behavior also has an impact on the formalization and procedures involved in implementing programs that are very inefficient, resulting in administrative delays on the other hand. Delays in the distribution of fertilizers and seeds, for example, may occur due to the complicated procedure that is carried out by the same actors. It is hoped that information transparency and flexibility in carrying out the roles and functions of actors are expected to meet all public needs related to this food diversification program.

\section{The Strength of Resource Dependencies}

In this sector, the policy network is focused on members of the network group who depend on each other for important resources such as finance, expertise and legitimacy or are some of them only temporary actors who are relatively independent of one another. The first is financial, based on field observations the actors involved depend on each other. The dependence of the actors from the financial side is shown when the program is implemented, financial sharing is needed to complete the local food diversification program. Such as strengthening public consumption patterns to switch to consumption of sweet potatoes and maize, the street level bureaucracy, in this case counseling and other field officers, really hope that the financial assistance available from this diversification program is from both the central and local governments.

Second, the expertise of the actors involved is of course different so they need cooperation in the completion of each program that is implemented. Relative decision-making requires expertise in seeing and analyzing existing problems that will make them a team that is able to collaborate in the same forum. And third, in terms of legitimacy. The actors certainly do not have the same legitimacy. In one organization that was formed as an instrument in the implementation of verification of food, the type of legitimacy obtained was different. Some of them have full authority in decision making in various conditions because of their status who have become permanent members of the organization and some are still selfsufficient. This has an impact on the forms of discretion taken by actors tend to be different and unable to accommodate all public needs.

The hope is that with the policy network concept approach, the actors will be able to maximize the forms of discretion taken in addition to facilitating and responding to public needs as well as solving classic convoluted and hierarchical bureaucratic problems so that program implementation can be effective and have an impact on the good performance of policies.

\section{CONCLUSION}

The results showed that there was a red tape phenomenon in the bureaucracy, such as rigid and convoluted procedures as well as the formalization of hierarchical rules and structures that brought policy delays. In terms of the policy network sector, namely the relative stability of a network's membership, actors involved in decision making tend to be dominated by the same people, the involvement of actors who tend to be the same also results in decision making only being dominated by certain people; the network's relative insularity, components in a rigid structure and do not provide space for other groups who have the same interests and goals to be involved in decision making, become a problem that is quite difficult to overcome; the strength of resource dependencies, the dependence of the actors from the financial side is shown at the time of program implementation, it requires mutual financial sharing to complete the local food diversification program, the expertise of the actors involved is certainly different so they require cooperation in the completion of each program implemented, and some of them have full authority in decision making in various conditions due to their status as permanent members of the organization and some are still self-sufficient status. Of the three factors that have not been able to run effectively in 
accordance with what has been understood. In addition, the discretion taken by the actors has not been able to optimally answer the public's needs.

\section{ACKNOWLEDGMENT}

We would like to express our gratitude to the Provincial Government of South Sulawesi, especially the ranks of the South Sulawesi Province Food Security Service. In addition, we also express our gratitude to the Bone Regency Government, especially to the Head of the Food Security Service and staff who provided a lot of information regarding the implementation of the food diversification policy, both in the form of data and information that is very much needed in completing the stages in this research. And lastly, we would like to thank the team who have helped make this research process a success.

\section{REFERENCES}

[1] S. Serpa and C.M. Ferreira, "The Concept of Bureaucracy by Max Webber," International Journal of Social Science Studies, vol. 7, no. (2), p. 12,2019 .

[2] A. Dwiyanto, Ilmu Administrasi di Indonesia: Mencari Identitas. Yogyakarta: UGM Press, 2016.
[3] M. Lipsky, Street Level Bureaucracy: Dilemmas of Individual in Public Service. New York: Russel and Sage Foundation, 1980.

[4] A. Dwiyanto, Reformasi Birokrasi Publik di Indonesia. Yogyakarta: UGM Press, 2012.

[5] R.A.W. Rhodes, "Policy networks: a British perspective," Journal of Theoretical Politics, vol. 2, no. (2), pp. 293-317, 1990.

[6] M. Goggin, A. Bowman, L. O'Toole, and J.P. Lester, Implementation Theory and Practice: Toward a Third Generation. USA. Glennwood, IL: Scott Foresman/Litle, Brown, 1990.

[7] R.C. Chandler and J.C. Plano, The Public Administration Dictionary. US: John Wiley \& Sons, 1988.

[8] B. Bozeman, "A Theory of Government Red Tape," Journal of Public Administration Research and Theory, vol. 3, no. (3), pp. 273-304, 1993.

[9] B. Bozeman and M.K. Feeney, Rules and Red Tape: A Prism for Public Administration Theory and Research. London: M.E. Sharpe, 2011.

[10] M. Cole and G. Parston, Unlocking Public Value," USA: John Wilet \& Sons, Inc., 2006.

[11] S.M. Grindle, Politics, Policy Implementation in the Thirld World. New Jersey: Princenton University Press, 1980.

[12] R.B. Ripley, Policy Analysis in Policy Science. Chicago: Nelson-Hall Inc., 1985.

[13] L.J.Jr. O’Toole, "Interorganizational Relations in Impelementation," In B.G. Peters and J. Pierre, Handbook of Public Administration (Second Edition). London: Sage Publication, 2012.

[14] M.B. Miles and A.M. Huberman, Analisis Data Kualitatif. Translate by Tjetjep Rohendi Rohidi, 1992. Jakarta : Universitas Indonesia, 1984. 